\title{
Effect of insulin on ketone body clearance studied by a ketone body "clamp" technique in normal man
}

\author{
U. Keller, M. Lustenberger and W.Stauffacher \\ Department of Medicine and Department of Research Kantonsspital, University of Basel, Switzerland
}

\begin{abstract}
Summary. The effect of elevated plasma insulin concentration $(55 \pm 2 \mathrm{mU} / \mathrm{l})$ on peripheral clearance and production of total ketone bodies was determined using $3-{ }^{14} \mathrm{C}$-acetoacetate tracer infusions. Nine normal subjects were studied twice, once during insulin infusion $\left(20 \mathrm{mU} \cdot \mathrm{m}^{-2} \cdot \mathrm{min}^{-1}\right)$, once during basal plasma insulin concentrations (controls). Blood total ketone body concentrations (sum of acetone, acetoacetate and $\beta$-hydroxybutyrate) were maintained in both studies at $2 \mathrm{mmol} / \mathrm{l}$ by feedback-controlled sodium acetoacetate infusions. The coefficient of variation of total ketone body concentrations during the two clamp studies was 10 and $11 \%$ respectively. The sodium acetoacetate infusion rate required during the clamp was $55 \pm 4 \%$ higher during hyperinsulinaemia than in controls $(p<0.005)$. This was due to increased
\end{abstract}

total ketone body clearance $\left(8.4 \pm 0.7 \mathrm{vs} 6.7 \pm 0.4 \mathrm{ml} \cdot \mathrm{kg}^{-1}\right.$. $\left.\min ^{-1}, p<0.015\right)$, and to enhanced suppression of ketone body production $(p<0.01)$. Hyperketonaemia alone decreased ketone body production by $42 \%$ and diminished ketone body clearance by $46 \%$, the former being enhanced, the latter being in part antagonised by insulin. Since the plasma insulin concentrations were within those observed in patients treated for diabetic ketoacidosis, the data suggest that the antiketotic effect of insulin therapy results in part from an increase in peripheral ketone body disposal.

Key words: Ketone bodies, ketone body clearance, $\beta$-hydroxybutyrate, acetoacetate, ketogenesis, ketoacidosis, insulin, lipolysis.
Ketotic conditions such as fasting or diabetic acidosis are primarily the result of increased ketone body production $[1,2]$. In addition, diminished peripheral ketone body clearance plays a contributing role [2,3]. The question whether decreased ketone body clearance during diabetic ketoacidosis is a consequence of insulin deficiency or of the elevation of ketone body concentrations is controversial. Indirect evidence for a role of insulin in ketone body removal was suggested by the observation that ketone body concentrations in ketotic diabetic patients were higher than those observed in non-diabetic fasting subjects, although ketone body disposal rates were similar [2, 4]: however, a recent study demonstrated similar peripheral ketone body clearance rates in non-diabetic and in diabetic ketotic subjects [3]. Hyperketonaemia per se results in decreased metabolic clearance rate of ketone bodies in man [5-7].

Animal data are also equivocal since on one hand, ketone body clearance rates were decreased in diabetic animals $[8,9]$, and insulin therapy increased ketone body utilisation [10]; other studies failed to observe an effect of insulin on ketone body utilisation [11-14].
In view of these unresolved issues, the present studies were designed to examine the influence of hyperinsulinaemia on peripheral ketone body clearance in man, and to assess its interaction with elevated ketone body concentrations. To avoid a confounding effect of altered ketone body concentrations, they were maintained at predetermined levels using rapidly determined ketone body concentrations and variable rates of ketone body infusions (ketone body "clamp").

\section{Subjects and methods}

\section{Subjects and procedures}

Nine volunteers ( 5 men, 4 women) aged between 41 and 63 years (52 \pm 7 years), weighing $74 \pm 11 \mathrm{~kg}$, with a body mass index of $25.1 \pm 0.8 \mathrm{~kg} / \mathrm{m}^{2}$ gave their written informed consent to participate twice; once in the insulin protocol, once in the control study. They were taking no medication; their history and clinical examinations were unremarkable. A glucose tolerance test was normal according to the WHO criteria (1980), as were their plasma electrolytes, creatinine and liver enzymes. The study protocol was approved by the local ethics committee on human experimentation. 
After a 12-h overnight fast, they were admitted to the hospital; a teflon cannula was inserted into the left antecubital vein for infusions, and a butterfly needle in retrograde manner into a dorsal hand vein for sampling of arterialised blood [15]. After withdrawing blood for determination of recoveries of ${ }^{14} \mathrm{C}$-ketone bodies, a continuous infusion of $150 \mu \mathrm{Ci} 33^{-14}$-C-Na-acetoacetate was started by bolus injection of $20 \mu \mathrm{Ci}$ of the tracer. After $60 \mathrm{~min}$ of tracer equilibration, blood samples were drawn in 10-min intervals during a 30-min basal period and during $230 \mathrm{~min}$ of unlabelled acetoacetate infusion (ketone body "clamp"). During the acetoacetate infusion either insulin $\left(20 \mathrm{mU} \cdot \mathrm{m}^{-2} \cdot \mathrm{min}^{-1}\right)$ or saline (controls) were infused. All infusions were delivered using Harvard syringe pumps (Harvard Apparatus Ltd, South Natick, Mass, USA).

\section{Ketone body "clamp"}

Sodium acetoacetate was infused during the first $30 \mathrm{~min}$ at fixed rates $\left(42.5 \mu \mathrm{mol} \cdot \mathrm{kg}^{-1} \cdot \mathrm{min}^{-1}\right.$ during the first $10 \mathrm{~min}, 21.4 \mu \mathrm{mol}$. $\mathrm{kg}^{-1} \cdot \mathrm{min}^{-1}$ during the second $10 \mathrm{~min}$, and $11.6 \mu \mathrm{mol} \cdot \mathrm{kg}^{-1} \cdot \mathrm{min}^{-1}$ during the following $10 \mathrm{~min}$ ) to raise total ketone body (TK) concentrations acutely to $2.0 \mathrm{mmol} / 1$. Thereafter, the infusion rate of sodium acetoacetate was adjusted in 10-min intervals according to rapidly determined acetoacetate (including acetone) and $\beta$-hydroxybutyrate concentrations and to an algorithm. Since ketone body concentrations were only known with a 20 -min delay after sampling, the actual total ketone body concentration at time i was predicted by using the previous ketone body concentrations and acetoacetate infusion rates in the calculation. Thereby, the new acetoacetate infusion rate was calculated aiming to correct total ketone body concentrations to the desired value. Specifically, the average infusion rates of acetoacetate during the preceding $60 \mathrm{~min}$ were divided by the mean total ketone concentration, yielding thereby an estimation of the metabolic clearance rate (MCR) of total ketone bodies, neglecting the contribution of endogenous ketone body production to total turnover. The actual total ketone body concentration at time $i$ was predicted using the ketone body concentration $20 \mathrm{~min}$ previously, the calculated MCR at time i minus $20 \mathrm{~min}$, and the acetoacetate infusion rate during the preceding $20 \mathrm{~min}$. Thereafter, the new acetoacetate infusion rate was calculated from the difference between actual and target concentrations, using a volume of distribution (VD) of total ketone bodies of $0.2 \mathrm{l} / \mathrm{kg}$ [7], and aiming to correct total ketone bodies to the desired concentration within $30 \mathrm{~min}$.

The algorithm for calculation of sodium acetoacetate (AcAc infusion rate at time $\mathrm{i}$ to adjust total ketone body concentrations to $2 \mathrm{mmol} / \mathrm{l}$ ) is as follows:

(1) Estimated $T K-M C R_{(-20-60 \mathrm{~min})}^{\text {a }}=$ mean AcAc infusion rate ${ }_{(-20-60 \text { min) }}^{b}$ mean $[\mathrm{TK}]_{-20-60 \mathrm{~min})}$

(2) Predicted $[T K]_{i}(\mu \mathrm{mol} / \mathrm{l})=$

$$
[\mathrm{TK}]_{(\mathrm{i}-20 \mathrm{~min})} \cdot\left[(1) \cdot[\mathrm{TK}]_{(\mathrm{i}-20 \text { min })}-\text { AcAc infusion rate }{ }_{(\mathrm{i}-20 \mathrm{~min})}^{\mathrm{b}}\right] \cdot \frac{20 \mathrm{~min}}{\mathrm{VD}_{\mathrm{TK}}}
$$

(3) New AcAc infusion rate $(\mathrm{i}) \mathrm{b}=$

$$
\text { (1) } \cdot[\mathrm{TK}]_{(\mathrm{i}-20 \mathrm{~min})}+\left[\left(2.0 \mathrm{mmol} / 1-(2) \cdot \frac{\mathrm{VD}_{\mathrm{TK}}}{30 \mathrm{~min}}\right]\right.
$$

where ${ }^{\mathrm{a}}$ indicates $\mathrm{ml} \cdot \mathrm{kg}^{-1} \cdot \mathrm{min}^{-1}$ and ${ }^{\mathrm{b}} \mu \mathrm{mol} \cdot \mathrm{kg}^{-1} \cdot \mathrm{min}^{-1}$

\section{Infusions}

Unlabelled sodium acetoacetate and sodium-3- ${ }^{14} \mathrm{C}$-acetoacetate were prepared from ethylacetoacetate by hydrolysis with a slight excess of $\mathrm{Na}(\mathrm{OH})$ as described previously $[6,7]$. Concentration of unlabelled sodium acetoacetate was $1.45 \pm 0.19 \mathrm{mmol} / 1$; each infusate was calibrated by spectrophotometric assay [16]. Gas chromatography demonstrated that the infusate did not contain significant amounts of ethanol or acetone. Glucose $20 \%(\mathrm{w} / \mathrm{v})$ was infused at variable rates adjusted in 10-min intervals according to an algorithm to maintain euglycaemia during insulin infusion [17]. Radiochemical purity of the sodium $3-{ }^{14} \mathrm{C}$-acetoacetate (Radiochemical Centre, Amersham, UK) was assessed according to Mayes and Felts [18] and was 76.4 \pm $1.7 \%$. The tracer infusion rates were corrected accordingly. ActrapidHM was from Novo, Bagsvaerd, Denmark; it was dissolved in $0.9 \%$ $\mathrm{NaCl}$ containing $2 \%$ human albumin (Swiss Red Cross, Bern, Switzerland).

\section{Analyses}

Samples were collected in tubes containing EDTA $(5 \mathrm{mg} / \mathrm{ml}$ blood). $0.5 \mathrm{ml}$ blood was added to $60 \mathrm{ml}$ serum flasks containing $0.5 \mathrm{ml}$ perchlorid acid $30 \%(\mathrm{w} / \mathrm{v})$. The flasks were immediately stoppered with gastight rubber stoppers (Veneret, Paris, France), and incubated for $15 \mathrm{~min}$ in a waterbath at $80^{\circ} \mathrm{C}$. Preliminary studies demonstrated that after $15 \mathrm{~min}$, more than $99 \%$ of the acetoacetate had been decarboxylated to acetone; the serum flasks were punctured with the needle of a glass syringe, and $3 \mathrm{ml}$ of head space air was injected into a gaschromatograph (Packard, Mod. 427) equipped with a glass column packed with Carbopack c/0.2\%, 80/100; (Supelco, Bellefonte, Calif, USA), kept at $60^{\circ} \mathrm{C}$. Acetone consisting of decarboxylated acetoacetate and preexisting acetone eluted after $30 \mathrm{~s}$. All determinations were performed in duplicate, the concentrations were read from a standard curve obtained from headspace air of acetoacetate solutions in saline. Plasma $\beta$-hydroxybutyrate concentrations were determined rapidly by an enzymatic method [16] with the following modification: after obtaining plasma within $30 \mathrm{~s}$. (Beckman Microfuge), $0.2 \mathrm{ml}$ were added directly to $1.2 \mathrm{ml} 0.2 \mathrm{~mol} / 1$ glycine buffer containing $2.54 \mu \mathrm{mol}$ NAD (Sigma, St. Louis, Mo, USA) in a cuvette. $20 \mu$ l 3-D- $\beta$-hydroxybutyrate dehydrogenase (no. 1277833, Boeringer-Mannheim, FRG) was added, and the cuvettes were incubated at $60^{\circ} \mathrm{C}$ for $20 \mathrm{~min}$. Immediately thereafter, extinction of the samples was read at $340 \mathrm{~nm}$ (LKB photometer with automatic cuvette changer). Each sample was analyzed in triplicate, and a blank containing plasma but no enzyme was subtracted. Since the reaction came only to $60-70 \%$ completion, the concentrations were read from a standard curve prepared in plasma containing low endogenous $\beta$-hydroxybutyrate concentrations to which known amounts of $\beta$-hydroxybutyrate were added. Blood $\beta$-hydroxybutyrate was calculated from plasma concentrations by multiplying with 0.85 [16]. $\beta$-hydroxybutyrate concentrations determined by this method were equivalent to those determined by standard enzymatic methods [16]. Plasma glucose concentrations were measured within $5 \mathrm{~min}$ using a YSI glucose analyzer (Mod. 23A; Yellow Springs, Ohio, USA). Blood ${ }^{14} \mathrm{C}$-total ketone body concentrations were determined as described previously $[7,18]$. Recovery of $3-{ }^{14} \mathrm{C}$-acetoacetate and $3-{ }^{14} \mathrm{C}-\beta$-hydroxybutyrate added to preinfusion blood was $107 \pm 2 \%$, and $83 \pm 1 \%$, respectively, and corrections were made accordingly. Rates of production and metabolic clearance of total ketone bodies were calculated using a single compartment model of total ketone bodies and the combined specific activity of total ketone bodies in a non-steady state equation assuming a functional volume of distribution of total ketone bodies of $0.21 / \mathrm{kg}$ [7]. The mean specific activity ratio of total ketone bodies/acetoacetate was 0.55 in the basal state, and 0.95 during acetoacetate infusion. Endogenous ketone body production was the difference between the rate of appearance of total ketone bodies, and the infusion rate of sodium acetoacetate. Tracer kinetics were not calculated during the initial $45 \mathrm{~min}$ when steady state was grossly disturbed by the loading doses of sodium acetoacetate. Urinary excretion of acetoacetate was $1.6 \pm 0.3 \%$ of the infused unlabelled, and $1.7 \pm 0.6 \%$ of the labelled ketone body, and was neglected in the calculation of kinetic data. Plasma non-esterified fatty acids [19], plasma insulin [20], glucagon [21] and lactate [22] concentrations were determined as described.

\section{Statistical analysis}

All parameters of ketone body kinetics did not change significantly with time during the $30-\mathrm{min}$ basal period, and during the last $100 \mathrm{~min}$ of sodium acetoacetate infusion when tested by analysis of 


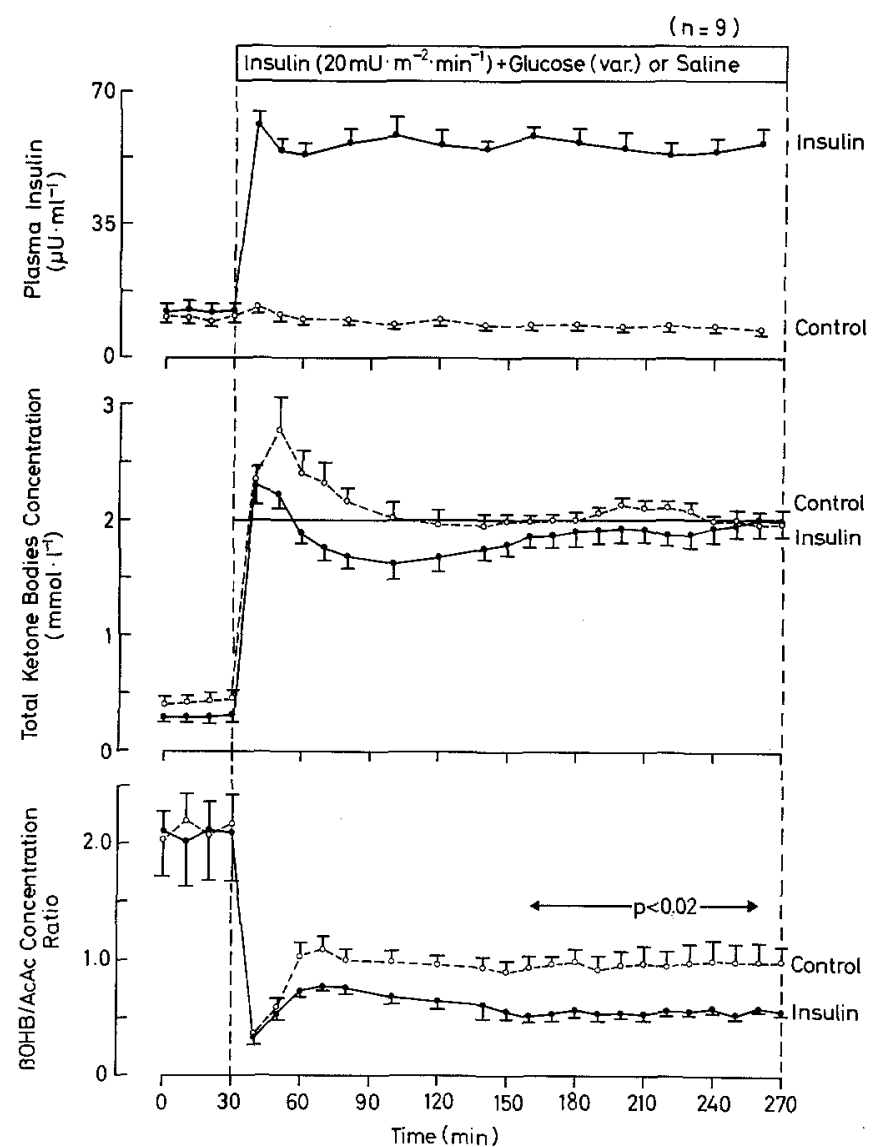

Fig. 1. Plasma insulin, total ketone body concentration and $\beta$-hydroxybutyrate/acetoacetate concentration ratio before and during the ketone body clamp. Nine overnight-fasted subjects received on two separate occasions either saline (control, dashed line) or insulin (full line). Results are mean $\pm S E M$

variance with repeated measures or by Friedman's analysis of variance. Hence, average values of these two periods were used to compare the two protocols. The changes from the basal period to the infusion period and the two protocols were compared by Student's paired t-test, and for non-normally distributed data by Wilcoxon's signed-rank test. Correlations were calculated according to Spearman. Statistical calculations were performed using standard software (BMDP-Statistical Software, Inc. Los Angeles, Calif, USA) and a Digital Vax System. Results are means \pm SEM.

\section{Results}

\section{Plasma insulin, total ketone body concentrations and $\beta$-hydroxybutyrate/ acetoacetate concentration ratio (Fig. 1)}

Plasma insulin concentrations $(12.1 \pm 1.9 \mathrm{mU} / 1$ increased rapidly during insulin infusion to steady state levels of $55.2 \pm 2.5 \mathrm{mU} / 1$; plasma insulin levels in the control studies decreased slightly from $10.4 \pm 1.4$ to $8.3 \pm 1.4 \mathrm{mU} / 1(p<0.05)$ during hyperketonaemia. Basal total ketone body concentrations were $0.30 \pm 0.05$ in the insulin protocol, and $0.43 \pm 0.06 \mathrm{mmol} / 1$ in controls; they increased rapidly during acetoacetate infu-

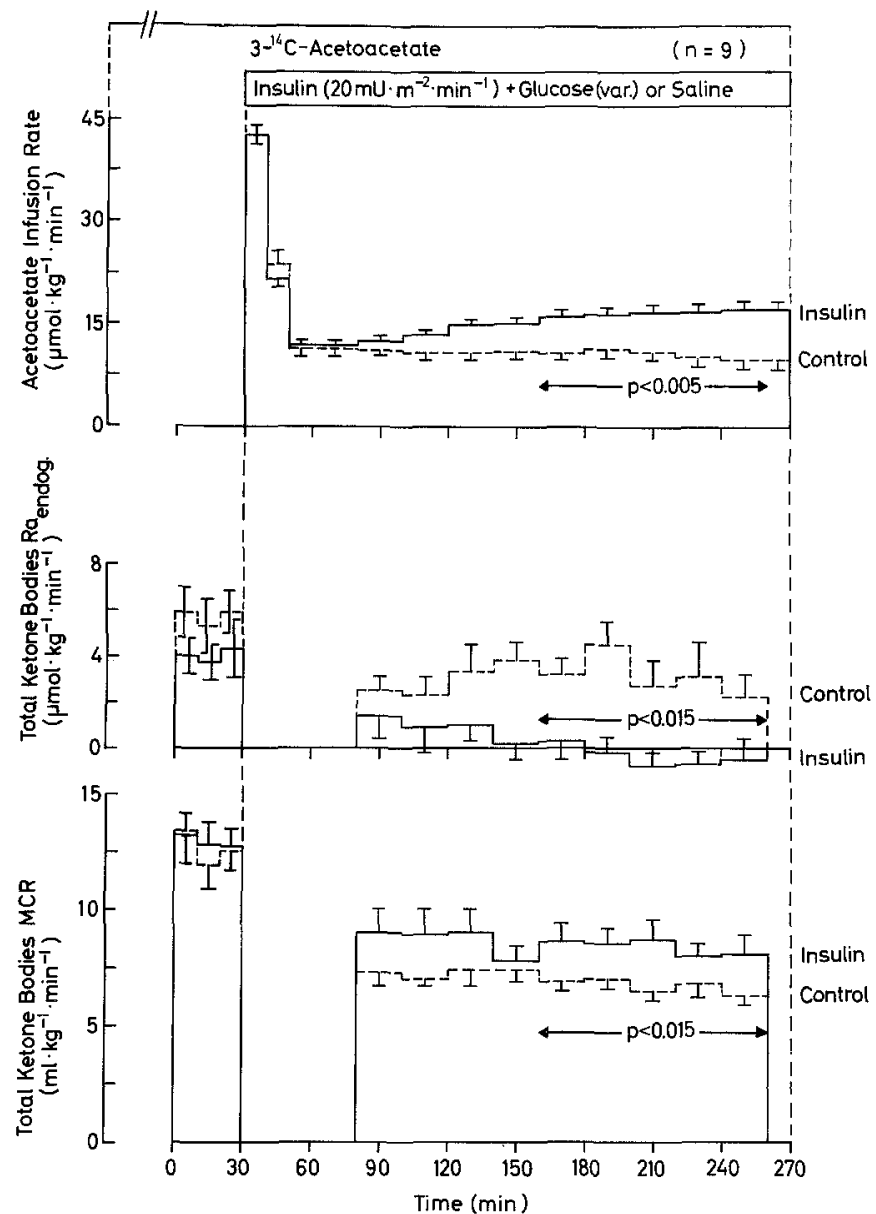

Fig. 2. Sodium-acetoacetate infusion rates, endogenous production (Ra) and peripheral clearance (MCR) of total ketone bodies before and during the ketone body clamp. The dashed line represents control studies, the full line the studies with elevated plasma insulin concentrations. $P$ values refer to statistical differences of the interval $150-270 \mathrm{~min}$ between the control and the hyperinsulinaemia protocols. Results are mean \pm SEM

sion and reached slightly lower levels in the insulin protocol than in controls during the initial $60 \mathrm{~min}$ of acetoacetate infusion. During the last $100 \mathrm{~min}$ of the "clamp" (steady state period), total ketone body concentrations were similar $(1.9 \pm 0.97$ and $2.04 \pm$ $0.03 \mathrm{mmol} / 1$ respectively); the coefficients of variation of total ketone body concentrations were 11 and 10\% respectively. The $\beta$-hydroxybutyrate/acetoacetate concentration ratios (bottom panel) during the basal period were $2.1 \pm 0.4$ and $1.9 \pm 0.2$ respectively; they decreased rapidly during acetoacetate infusion to lower values in the insulin protocol than in controls $(0.54 \pm$ 0.03 vs $0.97 \pm 0.10, p<0.02$ ).

\section{Sodium acetoacetate infusion rates, endogenous production and metabolic clearance rate of total ketone bodies (Fig. 2)}

Unlabelled acetoacetate was infused during the first $30 \mathrm{~min}$ in a predetermined stepwise fashion (see 


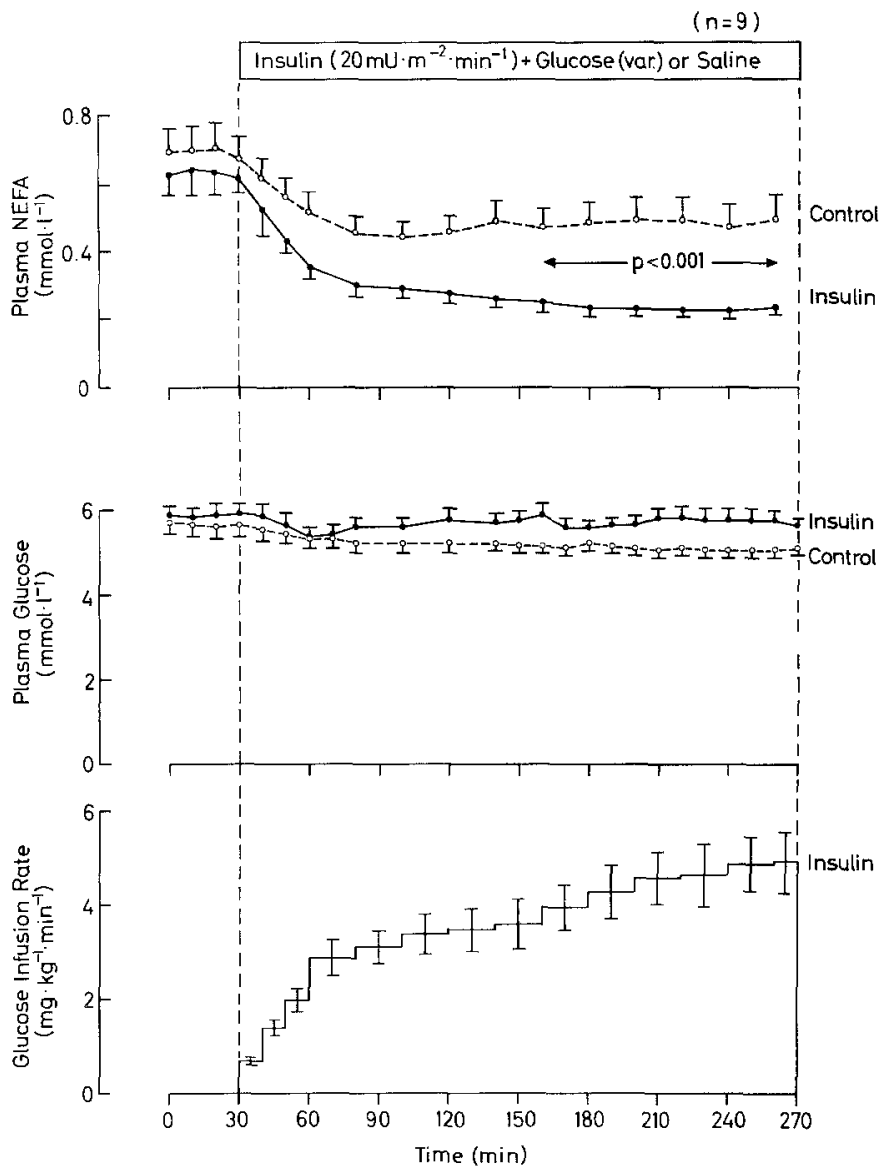

Fig. 3. Plasma concentrations of non-esterified fatty acids and glucose, and glucose infusion rates in control studies (dashed line) and during hyperinsulinaemia (full line). Results are mean \pm SEM

"Methods"); later on, its rate was on average $11 \mu \mathrm{mol} \cdot \mathrm{kg}^{-1} \cdot \mathrm{min}^{-1}$. During the last $100 \mathrm{~min}$, the acetoacetate infusion rate was $55 \%$ higher in the insulin protocol than in controls $(p<0.005)$. Endogenous ketone body production (middle panel) decreased significantly during acetoacetate infusion in both protocols; during the last $100 \mathrm{~min}$, ketone body production was entirely suppressed during insulin infusion to $-0.5 \pm 0.4 \mu \mathrm{mol} \cdot \mathrm{kg}^{-1} \cdot \mathrm{min}^{-1}(p<0.01$ vs basal period). In comparison, total ketone body production decreased in the control studies from $5.5 \pm 1.0$ to $3.2 \pm$ $1.0 \mu \mathrm{mol} \cdot \mathrm{kg}^{-1} \cdot \mathrm{min}^{-1}(42 \%, p<0.05)$; the decrease of production was smaller $(p<0.015)$ than in the insulin protocol. Total ketone body clearance decreased significantly during hyperketonaemia from $12.9 \pm 0.8$ to $8.4 \pm 0.7 \mathrm{ml} \cdot \mathrm{kg}^{-1} \cdot \mathrm{min}^{-1}$ during elevated insulin $(p<$ 0.01 ), and from $12.5 \pm 0.6$ to $6.7 \pm 0.4 \mathrm{ml} \cdot \mathrm{kg}^{-1} \cdot \mathrm{min}^{-1}$ $(p<0.001)$ in controls. Both the absolute values $(p<$ $0.015)$ and the changes from baseline $(p<0.025)$ were significantly different between hyperinsulinaemia and control studies. The insulin effect on the $\beta$-hydroxybutyrate/acetoacetate concentration ratio was significantly correlated with that of the acetoacetate infusion rate $(p<0.05)$.
Plasma concentration of non-esterified fatty acids (NEFA), glucagon, lactate, glucose and glucose infusion rate (Fig. 3)

Plasma NEFA concentration decreased significantly in both studies during acetoacetate infusion by $0.40 \pm$ $0.06 \mathrm{mmol} / 1 \quad(p<0.001)$ and by $0.21 \pm 0.04 \mathrm{mmol} / 1$ $(p<0.01)$ respectively. The decrease was $91 \%$ greater in the insulin protocol compared to controls $(p<0.001)$. Plasma glucose concentrations decreased slightly from $5.67 \pm 0.28$ to $5.11 \pm 0.17 \mathrm{mmol} / 1(p<0.01)$ during hyperketonaemia in the control studies whereas they were maintained at basal levels by the glucose clamp when insulin was administered. Plasma glucagon concentrations decreased slightly during hyperinsulinaemia from $64 \pm 39$ to $49 \pm 31 \mathrm{pg} / \mathrm{ml}$ compared to a change from $59 \pm 44$ to $69 \pm 58 \mathrm{pg} / \mathrm{ml}$ (NS) in controls. Plasma lactate concentrations increased significantly during hyperinsulinaemia from $1.14 \pm 0.15$ to $1.46 \pm$ $0.17 \mathrm{mmol} / 1(p<0.015)$; in contrast, plasma lactate remained unchanged during hyperketonaemia $(1.06 \pm$ 0.13 in the control period, $1.02 \pm 0.15 \mathrm{mmol} / 1$ during hyperketonaemia, $p<0.01$ vs hyperinsulinaemia protocol).

\section{Discussion}

The data of the present study demonstrated a stimulatory effect of elevated plasma insulin concentration on ketone body clearance in man. Previous reports demonstrated that ketone body clearance was diminished in insulin-deficient ketotic humans [2,23] and animals [9-11]. However, these data were not conclusive since hyperketonaemia per se results in decreased ketone body clearance as demonstrated previously [5-7] and in the present study.

When insulin was administered to dogs [10] and to humans $[4,24,25]$ ketone body clearance decreased. However, the conclusion of two of these studies [24, 25 ] may be challenged by the fact that ketone body concentrations decreased during insulin infusion. In the studies in which infusions of unlabelled ketone bodies were used to assess ketone body utilisation [4, 10] the results can be critisised since two different models of ketosis were compared [10] and since the unphysiological racemate $\mathrm{D}, \mathrm{L}-\beta$-hydroxybutyrate was used to determine ketone body clearance [4]. In addition, ketone body disposal rates were determined without measuring endogenous ketogenesis during infusion of unlabelled ketone bodies [4]. Suppression of hepatic ketone body production occurred, however, in the present study in agreement with a previous report [6].

Regarding the mechanism of the insulin effect on ketone body clearance, an earlier study demonstrated a selective effect of insulin on $\beta$-hydroxybutyrate removal in rat diaphragm without an effect on acetoacetate utilisation [26]. Insulin administration to diabetic rats 
increased ketone body oxidation in heart mitochondria, along with a stimulation of the activity of $\beta$-hydroxybutyrate dehydrogenase and of 3-oxoacid CoAtransferase [27]. These findings may explain the present observation that the $\beta$-hydroxybutyrate/acetoacetate concentration ratio decreased during insulin administration. This decrease was probably not due to diminished de novo production of $\beta$-hydroxybutyrate, since $\beta$-hydroxybutyrate production was presumably small in both studies compared to the rate of acetoacetate infusion. A considerable amount of $\beta$-hydroxybutyrate can be expected to be converted from infused acetoacetate in the liver [28] and in peripheral tissues [29, 30]. The present findings suggest, therefore, that hyperinsulinaemia increased total ketone body removal mainly by increasing $\beta$-hydroxybutyrate clearance. Although we have no direct measurements of individual ketone body clearance this conclusion is consistent with a previous report demonstrating decreased clearance of $\beta$-hydroxybutyrate but not of acetoacetate in diabetic patients $[23,30]$. It is possible that label exchange during acetoacetate infusion resulted in a spuriously increased rate of appearance of ketone bodies [31]; however, this should have occurred in both protocols.

Elevation of plasma insulin concentrations enhanced the decrease of plasma NEFA levels observed during hyperketonaemia per se, probably due to augmented suppression of lipolysis by elevated ketone body concentrations [6]. It is possible that the insulininduced lowering of plasma NEFA concentrations contributed to the observed increase in ketone body clearance, e.g. by competition of NEFA with ketone bodies for uptake in peripheral tissues. Previous data on the interaction of NEFA and ketone bodies in peripheral tissues are inconclusive; ketone body utilisation was unchanged when NEFA availability was increased in muscle in fasted rats [32]; however, body utilisation was diminished in human adipose tissue during elevated NEFA concentrations [33].

A further mechanism whereby insulin affected ketone body clearance may have been related to its effect on glucose uptake; this point is also not clearly resolved in the literature since in vitro studies showed that glucose had either no effect on ketone body utilisation [34] or inhibited acetoacetate oxidation in adipose tissue [35] and in brain [36].

The present studies represent the first attempt to assess peripheral ketone body clearance at predetermined ketone body concentrations using a ketone body "clamp". Thereby, regulation of ketone body clearance can be studied independently of changes in ketone body concentrations even when ketone body production is altered. The results demonstrate that it is possible to reach the desired total ketone body concentrations within a narrow range, below that known to influence peripheral ketone clearance [3]. The algorithm used to adjust the acetoacetate infusion rate has some similarities to that described for the glucose clamp technique [17]. However, the ketone body clamp has two peculiarities: first, assay of $\beta$-hydroxybutyrate is slower than that of glucose due to unfavourable kinetic properties; attempts have been made previously to accelerate analysis time [3] but with limited success; second, the ketone body clamp is more labour-intensive since it requires measurement of two ketone bodies.

The observed increase in plasma lactate concentrations during hyperinsulinaemia may be explained by increased insulin-induced glucose uptake, and resultant glycolysis in peripheral tissues such as muscle. In addition, inhibition of gluconeogenesis may have decreased lactate uptake.

Endogenous ketone body production was completely suppressed during hyperinsulinaemia and elevated ketone body concentrations; this may have resulted from the combined effect of diminished plasma NEFA concentrations, from a direct suppressive effect of ketone bodies on ketogenesis [6], and from a direct inhibitory effect of insulin on hepatic ketogenesis [38].

In conclusion, the present results demonstrate that elevated insulin concentrations result in increased rates of ketone body clearance. Since plasma insulin concentrations achieved in the present study are in a similar range to those observed during treatment of diabetic ketoacidosis [39] the results suggest that insulin therapy has a peripheral hypoketonaemic effect. Conversely, diminished peripheral ketone body clearance may enhance the development of hyperketonaemia in insulin-deficient diabetic patients. However, it should be pointed out that the effect on ketone body clearance was observed at elevated insulin concentrations which does not occur spontaneously during conditions of hyperketonaemia; in addition, the stimulatory effect of insulin on ketone body clearance was weaker than the inhibitory effect of hyperketonaemia. This emphasizes the importance of studying ketone body clearance at predetermined ketone body concentrations as attempted in the present study by the ketone body "clamp". The technique should be suitable to study other mechanisms influencing ketone body uptake, such as substrates and hormones.

Acknowledgements. Supported by grant no.3.898.083 of the Swiss National Science Foundation (SNSF). UK was a recipient of a career development award of the SNSF. The technical assistance of G. Chollet and B. Vuattoux is gratefully acknowledged. Skilled secretarial assistance was provided by R. Moser and M.Oberli.

\section{References}

1. Owen OE, Block BSB, Patel M, Boden G, McDonough M, Kreulen T, Shuman CR, Reichard G jr (1977) Human splanchnic metabolism during diabetic ketoacidosis. Metabolism 26:381-398

2. Miles JM, Rizza RA, Haymond MW, Gerich JE (1980) Effects of acute insulin deficiency on glucose and ketone body turnover in man. Diabetes 29: 926-993 
3. Fery F, Balasse EO (1985) Ketone body production and disposal in diabetic ketoacidosis. Diabetes 34: 326-332

4. Sherwin RS, Hendler RG, Felig Ph (1976) Effect of diabetes mellitus and insulin on the turnover and metabolic response to ketones in man. Diabetes 25: 776-784

5. Owen OE, Reichard GA jr, Markus H, Boden G, Mozzoli MA, Shuman CR (1973) Rapid intravenous sodium acetoacetate infusion in man. Metabolic and kinetic responses. J Clin Invest 52: 2606-2616

6. Balasse EO, Neef MA (1975) Inhibition of ketogenesis by ketone bodies in fasting humans. Metabolism 24: 999-1007

7. Keller U, Sonnenberg GE, Stauffacher W (1981) Validation of a tracer technique to determine nonsteady state ketone body turnover rates in man. Am J Physiol 240: E253-E262

8. Chaikoff IL, Soskin S (1928) The utilization of acetoacetic acid by normal and diabetic dogs before and after evisceration. Am J Physiol 87: 58-72

9. Ruderman NB, Goodman MN (1974) Inhibition of muscle acetoacetate utilization during diabetic ketoacidosis. Am J Physiol 226: $136-143$

10. Balasse EO, Havel RJ (1971) Evidence for an effect of insulin on the peripheral utilization of ketone bodies in dogs. J Clin Invest 50: $801-813$

11. Bates MW (1972) Effect of hydroxybutyrate infusion and insulin injection on ketone body turnover of rats. Am J Physiol 222: $462 \sim 467$

12. Söling HD, Garlepp HJ, Creutzfeldt W (1965) Die Wirkung von Insulin und Glukose auf die Ketonkörperaufnahme total eviszerierter, normaler, hungernder und alloxan-diabetischer Ratten. Biochim Biophys Acta 100: 530-543

13. Williamson JR, Krebs HA (1961) Acetoacetate as a fuel of respiration in the perfused rat heart. Biochem $J$ 80: 540-547

14. Herndon ChM, Schade DS, Eaton RPh (1979) The differential effect of insulin in vivo on the peripheral utilization of glucose and ketone bodies in the rat. Horm Metab Res 11: 270-275

15. Sonnenberg GE, Keller U (1982) Sampling of arterialized heatedhand venous blood as in a noninvasive technique for the study of ketone body kinetics in man. Metabolism 31:1-5

16. Williamson DH, Mellanby J, Krebs HA (1962) Enzymatic determination od $\mathrm{D}$ - $\beta$-hydroxybutyrate acid and acetoacetic acid in blood. Biochem J 82: 90-96

17. De Fronzo RA, Tobin JD, Andres R (1979) Glucose clamp technique: a method for quantifying insulin secretion and resistance. Am J Physiol 237: E214-E223

18. Mayes PA, Felts JM (1967) Determination of ${ }^{14} \mathrm{C}$-labelled ketone bodies by liquid-scintillation counting. Biochem $\mathrm{J} 102$ : 230-235

19. Ho RJ (1970) Radiochemical assay of long-chain fatty acids using $63 \mathrm{Ni}$ as tracer. Analyt Biochem 36: 105-113

20. Heding LG (1972) Determination of total serum insulin in insulintreated diabetic patients. Diabetologia 8: 260-266

21. Aguilar-Parada E, Eisentraut AM, Unger RH (1969) Pancreatic glucagon secretion in normal and diabetic subjects. Am J Med Sci (1969) 257: 415-419

22. Passonneau JV (1974) L-(+)-Lactate. Fluorimetric method. In: Bergmeyer HU (ed) Methods of enzymatic analysis, 2nd edn. Academic Press, New York, pp 1515-1518

23. Nosadini R, Avogaro A, Trevisan R, Duner E, Marescotti C, Iori E, Cobelli C, Toffolo G (1985) Acetoacetate and $\beta$-hydroxybutyrate kinetics in obese and insulin-dependent diabetic humans. Am J Physiol 248: 611-620

24. Sonnenberg GE, Stauffacher W, Keller U (1982) Failure of glucagon to stimulate ketone body production during acute insulin deficiency or insulin replacement in man. Diabetologia 23: 94-100

25. Miles JM, Haymond MW, Nissen SL, Gerich JE (1983) Effects of free fatty acid availability, glucagon excess, and insulin deficiency on ketone body production in postabsorptive man. $\mathrm{J}$ Clin Invest 71: 1554-1561

26. Neptune EM jr, Sudduth HC, Fash FJ, Reish JJ jr (1961) Metabolism of $\beta$-hydroxybutyrate and acetoacetate by excised rat diagphragm and diaphragm homogenate. Am J Physiol 201: $235-238$

27. Grinblat L, Pacheco Bolanos LF, Stoppani AOM (1986) Decreased rate of ketone-body oxidation and decreased activity of D-3-hydroxybutyrate dehydrogenase and succinyl-CoA:3oxo-acid CoA-transferase in heart mitochondria of diabetic rats. Biochem J 240: 49-56

28. Keller U, Cherrington AD, Liljenquist JE (1978) Ketone body turnover and hepatic ketone production in fasted and in diabetic dogs. Am J Physiol 235: E238-E247

29. Hagenfeldt L, Wahren J (1986) Human forearm muscle metabolism during exercise, III. Uptake, release and oxidation of - hydroxybutyrate and observations on the -hydroxybutyrate-acetoacetate ratio. Scand J Clin Lab Invest 21: 314-320

30. Hall SEH, Wastney ME, Bolton TM, Braaten JT, Berman M (1984) Ketone body kinetics in humans: the effects of insulin-dependent diabetes, obesity, and starvation. J Lipid 25: 1184-1194

31. Landau BR (1986) A potential pitfall in the use of isotopes to measure ketone body production (letter) Metabolism 35: 94-95

32. Owen OE, Marks H, Sarshik S, Mozzoli M (1973) Relationship between plasma and muscle concentrations of ketone bodies and free fatty acids in fed, starved and alloxan-diabetic states. Biochem J 134: 499-506

33. Kissebah AH, Tulloch BR, Fraser TR (1974) Interrelationship between glucose and acetoacetate metabolism in human adipose tissue. Diabetologia 10:69-75

34. Williamson JR, Krebs HA (1961) Acetoacetate as fuel of respiration in the perfused rat heart. Biochem J 80:540-547

35. Söling HD, Zahlten R, Reimold WV, Wilms B (1970) Utilization of ketone bodies by adipose tissue and its regulation by carbohydrate metabolism. Horm Metab Res 2: 56-61

36. Ide T, Steinke J, Cahill GF jr (1969) Metabolic interactions of glucose, lactate and $\beta$-hydroxybutyrate in rat brain slices. Am $\mathbf{J}$ Physiol 217: 784

37. Alberti KGMM, Hockaday TDR (1972) Rapid blood ketone body estimation in the diagnosis of diabetic ketoacidosis. $\mathrm{Br}$ Med J 2: 565-568

38. Gamble MS, Cook GA (1985) Alteration of the apparent KM of carnitine palmitoyltransferase for malonyl-CoA by diabetic state and reversal by insulin. J Biol Chem 260: 9516-9519

39. Schade DS, Eaton RP, Alberti KGMM, Johnston DG (1981) Diabetic coma. Ketoacidotic and hyperosmolar. University of New Mexico Press, USA

Received: 26 June 1987

and in revised form: 3 November 1987

Dr. U.Keller

Department of Medicine

Division of Endocrinology and Metabolism

Kantonsspital

CH-4031 Basel

Switzerland 